\title{
The importance of sex as a risk factor for hospital readmissions due to pulmonary diseases
}

\author{
Alessandra Buja ${ }^{1 *}$ D, Anna De Polo², Elisa De Battisti ${ }^{2}$, Milena Sperotto', Tatjana Baldovin', Silvia Cocchio', \\ Patrizia Furlan ${ }^{1}$, Mario Saia ${ }^{3}$, Maria Luisa Scapellato', Guido Viel ${ }^{4}$, Vincenzo Baldo ${ }^{1}$, Chiara Bertoncello ${ }^{1}$ and \\ Mark Ebell
}

\begin{abstract}
Background: Pulmonary diseases are a common and costly cause of 30-day readmissions. Few studies have focused on the difference in risk for rehospitalization between men and women in older patients. In this study we analyzed the association between sex and the risk of readmission in a cohort of patients admitted to the hospital for chronic obstructive pulmonary disease (COPD) exacerbation and other major pulmonary diseases.

Methods: This was a retrospective cohort study based on administrative data collected in the Veneto Region in 2016. We included 14,869 hospital admissions among residents aged $\geq 65$ years for diagnosis related groups (DRGs) of the most common disorders of the respiratory system: bronchitis and asthma, pneumonia, pulmonary edema, respiratory failure, and COPD. Multilevel logistic regressions were performed to test the association between 30-day hospital readmission and sex, adjusting for confounding factors.

Results: For bronchitis and asthma, male patients had significantly higher odds of 30-day readmission than female patients (adjusted odds ratio (aOR), 2.07; 95\% confidence interval (Cl), 1.11-3.87). The odds of readmission for men were also significantly higher for pneumonia (aOR, 1.40; 95\% Cl, 1.13-1.72), for pulmonary edema and respiratory failure (aOR, 1.28; 95\% Cl, 1.05-1.55), and for COPD (aOR, 1.34; 95\% Cl, 1.00-1.81).

Conclusions: This study found that male sex is a major risk factors for readmission in patients aged more than 65 years with a primary pulmonary diagnosis. More studies are needed to understand the underlying determinants of this phenomena and to provide targets for future interventions.
\end{abstract}

Keywords: Pulmonary disease, Readmission risk, Sex differences, Elderly people

\section{Background}

Countries with developed healthcare systems are working to reduce unnecessary hospital readmissions to reach the triple aim of reducing costs, improving patient satisfaction, and improving health. Readmissions impact both health and satisfaction of patients, as multiple hospitalizations of subjects with chronic comorbidities are associated with emotional distress, loss of function, nosocomial infections, and increased mortality [1]. Moreover, hospital readmissions are also considered an index of low-quality care and

\footnotetext{
* Correspondence: alessandra.buja@unipd.it

'Department of Cardiological, Thoracic and Vascular Sciences, Hygiene and Public Health Unit, University of Padua, Via Loredan 18, 35128 Padova, Italy Full list of author information is available at the end of the article
}

in some health systems incur financial penalties for hospitals [2]. It is therefore important to analyze which factors lead to readmissions and to develop efficient strategies to reduce unnecessary readmissions, both at the hospital and health system levels.

Among the top 20 causes of readmission within 30 days are several respiratory diagnoses, including respiratory insufficiency and respiratory arrest (3rd place), COPD and bronchiectasis (9th place), and aspiration pneumonia (11th place) [3]. While several studies have analyzed the risk factors for rehospitalization in patients with pulmonary disease, few have focused on the difference in risk between men and women. In this study we analyzed data from a cohort of patients from the Veneto Region to

(c) The Author(s). 2020 Open Access This article is distributed under the terms of the Creative Commons Attribution 4.0 International License (http://creativecommons.org/licenses/by/4.0/), which permits unrestricted use, distribution, and reproduction in any medium, provided you give appropriate credit to the original author(s) and the source, provide a link to the Creative Commons license, and indicate if changes were made. The Creative Commons Public Domain Dedication waiver (http://creativecommons.org/publicdomain/zero/1.0/) applies to the data made available in this article, unless otherwise stated. 
determine the association between sex of the patient and readmission to the hospital. The ultimate goal is to use this information to help tailor a discharge program to prevent readmission and waste in resource use.

\section{Methods}

In the Veneto Region, regional authorities coordinate and control local health units (LHU), each of which is a separate unit in the Italian National Health Service (NHS). The NHS plans and delivers health services, primary care, and hospital care to its local community, based on a regional health plan. This was a retrospective cohort study conducted in any facility operating under the NHS in the Veneto Region in 2016 (population 4,907,529).

In order to select the "Index Admissions" (IA), we included diagnosis-related groups (DRGs) of common respiratory diagnoses involving residents aged $\geq 65$ years: bronchitis and asthma (DRG 96 and 97); pneumonia (DRG 89 or 90 ); pulmonary edema and respiratory failure (DRG 87); and COPD (DRG 88). We excluded patients meeting the following criteria: admission with International Classification of Diseases 9th revision clinical modification (ICD-9CM) principal diagnostic codes cancer (140._-239._), admission with psychiatric DRG (425-433 and 523), admission with DRG of chemotherapy and radiotherapy (409, 410, 492), admissions for day hospital care or rehabilitation, and those concerning patients residing outside the region. We also excluded as IA whose discharge was due to voluntary discharge, transfer to another public or private care institution for acute cases, transfer to another ward of the same structure, or transfer to a rehabilitation institute. If the same patient was admitted to hospital for the same condition several times, all the admissions were considered as IA. "Hospital readmission" was defined as the same patient readmitted for the same disease within 30 days of the IA.

Multilevel logistic regression models were created with hospital readmissions within 30-days for each pulmonary condition above as the dependent variable (attributing a value of 1 for each indicator associated with a readmission, as defined earlier) and considering the sex as the independent variable. Potential confounders included at first admission level: age as a continuous variable, formal education (university, high school, middle school and no education/ primary school), citizenship (Italian/Not Italian), length of stay as continuous variable, type of discharge (at home, at home with domiciliary care, residential care), and the Charlson Comorbidity Index (CCI) as a continuous variable; at second level the type of care institute (university, not university). The Charlson Comorbidity Index measures the comorbidities inside each hospital admission and is an extensively used comorbidity index with predictive validity for a range of outcomes, including readmission and death. The CCI comprises 19 medical conditions weighted 1-6 on the basis of their association with mortality.
Statistical analyses were performed using STATA software, version 12.1. All $p$-values reported are two-sided and results with $p$-values below 0.05 were considered statistically significant.

\section{Results}

During the period considered, we identified 1140 admissions for bronchitis and asthma, 6258 admissions for pneumonia, 5260 admissions for pulmonary edema and respiratory failure and 2211 admissions for COPD, collected in the Veneto Region in 2016.

The sample's characteristics are shown in Table 1 . Table 2 shows the number of Index Admissions and the percentage of readmissions overall and by sex for selected respiratory conditions: the frequency of readmission was statistically higher for men in all the considered cases.

Table 3 shows the results of the multilevel logistic regression analyses. For bronchitis and asthma, male patients showed twofold higher odds of being readmitted than female patients (aOR, 2.07; 95\% CI, 1.11-3.87). Significant associations with sex also emerged for pneumonia (aOR, 1.40 ; $95 \% \mathrm{CI}, 1.13-1.72$ ), for pulmonary edema and respiratory failure (aOR, 1.28; 95\% CI, 1.05-1.55) and for COPD (aOR, 1.34; 95\% CI, 1.00-1.81).

\section{Discussion}

This population-based study found that male sex is a risk factor for readmission in patients aged more than 65 years admitted to hospital with the diagnosis of several common respiratory diseases: bronchitis and asthma, pneumonia, pulmonary edema and respiratory failure and COPD.

This sex gap has been reported previously in other studies conducted in various settings, where male sex is indicated as an independent risk factor for readmission for COPD [4, 5]. Dal Negro [6], analyzing Italian patients diagnosed with COPD, chronic bronchitis and emphysema, concludes that direct costs for management are higher in male than in female patients. Moreover, this study draws attention to the fact that the major part of direct costs for the management of this diseases is yielded by the inpatient hospitalization. As regards pneumonia, our findings are concordant with literature data, which shows that women have less risk to be readmitted for pneumonia than men [7].

This relevant phenomenon is difficult to explain clinically but could be due to management of disease after discharge. In fact, men report less help-seeking behavior, which may delay accessing care when it is needed [8]. Moreover, men use primary care health services less frequently than women, are less involved in preventive initiatives and are less health literate [9]. For instance, it has been seen that fewer men understand and attend their follow-up appointments after acute hospitalization compared with women [10]. 
Table 1 Characteristics of adults aged 65 years and older years hospitalized for selected pulmonary diseases in 2016, Veneto region. (SD: standard deviation)

\begin{tabular}{|c|c|c|c|c|c|}
\hline & & $\begin{array}{l}\text { Bronchitis and } \\
\text { asthma }(N=1140)\end{array}$ & $\begin{array}{l}\text { Pneumonia } \\
(N=6258)\end{array}$ & $\begin{array}{l}\text { Pulmonary edema and } \\
\text { respiratory failure }(N=5260)\end{array}$ & $\operatorname{COPD}(N=2211)$ \\
\hline \multirow[t]{2}{*}{ Gender } & Male & 445 & 3220 & 2580 & 1152 \\
\hline & Female & 695 & 3038 & 2680 & 1059 \\
\hline \multirow[t]{2}{*}{ Age } & $65-84$ yr & 624 & 3407 & 3323 & 1378 \\
\hline & Over 84 yr & 516 & 2851 & 1937 & 833 \\
\hline \multirow[t]{2}{*}{ Citizenship } & Italian & 1124 & 6215 & 5191 & 2185 \\
\hline & Other & 16 & 43 & 69 & 26 \\
\hline \multirow[t]{4}{*}{ Formal education } & University & 17 & 98 & 74 & 33 \\
\hline & High school & 48 & 319 & 258 & 112 \\
\hline & Middle school & 194 & 1102 & 996 & 413 \\
\hline & Primary school or none & 881 & 4739 & 3932 & 1653 \\
\hline \multirow[t]{2}{*}{ Charlson Comorbidity Index } & No comorbidities & 645 & 2723 & 1255 & 1124 \\
\hline & At least one comorbidity & 495 & 3535 & 4005 & 1087 \\
\hline \multirow[t]{2}{*}{ Type of care institute } & University hospital & 92 & 753 & 632 & 257 \\
\hline & Other & 1048 & 5505 & 4628 & 1954 \\
\hline Length of stay in the care institute & $($ mean $\pm S D)$ & $8,49 \pm 4,98$ & $11,66 \pm 7,13$ & $12,55 \pm 7,80$ & $9,59 \pm 5,80$ \\
\hline \multirow[t]{3}{*}{ Type of discharge } & Home & 1029 & 5642 & 4714 & 2036 \\
\hline & Home with domiciliary care & 51 & 300 & 142 & 104 \\
\hline & Residential care & 60 & 496 & 404 & 71 \\
\hline
\end{tabular}

Help-seeking behavior is a complex phenomenon in which gender plays a fundamental role.

Masculine attitudes, behavior and values in general could lead to men ignoring symptoms of ill-health and failing to seek help from the health services because they see it as a sign of weakness [11]. Risk-taking behaviors are also more strongly associated with male role models [12]: in many cultures, the use of tobacco (a major risk factor for several lung diseases and associated with their severity) is closely linked with the perception of being a "real man" [13]. Some biological factors may also influence the higher risk of rehospitalization for pneumonia in men. For instance, men have a weaker immune response and have also been shown to have more chronic mucus hypersecretion, which may worsen their prognosis and increase the likelihood of death [7]. The association of sex with post- hospitalization risk is complex, and likely to be influenced by multiple factors. However, whatever the causes of the phenomenon, it is important to think about how to prevent readmissions.

Indeed, it could be useful to talk about gender-based medicine and prevention strategies, in order to address the resources in the most efficient way to reduce readmission rate and, consequently, costs for the health system.

To achieve this goal, it is important to give male patients adequate access to providers and personnel of intermediate and long-term care plans [14].

In particular, currently, there are few studies that evaluate the effectiveness of interventions that promote the access of men to primary care. A recent review found that physical activity, education, peer support-based interventions improve quality of life in men with long-term conditions [15].

Table 2 Number of index admissions and \% of readmissions overall and by sex for selected pulmonary diseases in adults age 65 years and older in 2016, Veneto Region

\begin{tabular}{|c|c|c|c|c|c|c|}
\hline & \multicolumn{2}{|l|}{ Total } & \multicolumn{2}{|l|}{ Male } & \multicolumn{2}{|c|}{ Female } \\
\hline & IA & $\% R^{a}$ & IA & $\% R^{a}$ & IA & $\% \mathrm{R}^{\mathrm{a}}$ \\
\hline Bronchitis and asthma & 1140 & 4.1 & 445 & $5.6^{\dagger}$ & 695 & 3.2 \\
\hline Pneumonia & 6258 & 6.5 & 3220 & $7.3^{+}$ & 3038 & 5.7 \\
\hline Pulmonary edema and respiratory failure & 5260 & 9.5 & 2580 & $10.4^{\dagger}$ & 2680 & 8.6 \\
\hline COPD & 2211 & 9.5 & 1152 & $10.8^{\dagger}$ & 1059 & 8.1 \\
\hline
\end{tabular}

${ }^{a} R$ readmissions (patients hospitalized again for the same disease within 30 of their $I A$ ) 
Table 3 Gender as a risk factor of readmission for selected pulmonary diseases in adults aged 65 years and older, by multivariate logistic regression analysis

\begin{tabular}{ll}
\hline Disease & $\begin{array}{l}\text { Odds ratio }(95 \% \\
\text { confidence interval) } \\
\text { Male vs Female }\end{array}$ \\
\hline Bronchitis and asthma & $2.07(1.11-3.87)$ \\
Pneumonia & $1.40(1.13-1.72)$ \\
Pulmonary edema and & $1.28(1.05-1.55)$ \\
respiratory failure & \\
COPD & $1.34(1.00-1.81)$ \\
\hline
\end{tabular}

Adjusted for: age, formal education, citizenship, length of stay, Charlson Comorbidity Index, type of discharge, type of care institute Results in bold are statistically significant $(p<0.05)$

More studies are needed to understand what is successful in improving elderly men's health and reducing the risk of readmission.

This study relied on routinely-collected administrative data, which unfortunately provides no information on the severity of a patient's disease, which is a variable strongly associated with the probability of readmission. In this context, length of stay during the first hospitalization could serve as a vague "proxy" of this aspect, and it was used as possible confounder.

\section{Conclusions}

This study found that male sex is a risk factors for readmission in patients aged more than 65 years with several pulmonary diseases.

More studies taking sex perspective into account are needed in order to provide targets for patient management interventions.

\section{Abbreviations \\ aOR: adjusted odds ratio; CCl: Charlson Comorbidity Index; Cl: Confidence interval; COPD: Chronic obstructive pulmonary disease; DRG: Diagnosis related group; IA: Index admission; ICD-9-CM: International Classification of Diseases 9th revision clinical modification; LHU: Local Health Unit; NHS: National Health Service; R: Readmissions; SD: Standard deviation}

\section{Acknowledgements}

Not applicable.

\section{Authors' contributions}

AB conceived the work and coordinated all study phases. VB obtained funding, coordinated all study phases, read and approved the final manuscript as submitted. MSp carried out the statistical analyses, read and approved the final manuscript as submitted. MSa coordinated and supervised data collection, revised and approved the final manuscript as submitted. SC, PF, MLS, GV and ME obtained funding, designed the data collection tools, revised and approved the final manuscript as submitted. AD, $E D B, C B, T B$ drafted the manuscript, read and approved the final manuscript as submitted. All authors read and approved the final manuscript.

\section{Funding}

The Department of Cardiologic, Vascular, and Thoracic Sciences and Public Health, University of Padua, funded this research with a competition for grants designed to stimulate collaboration between colleagues within the department. The Department had no role in the design of the study, the collection, analysis, or interpretation of the data, the writing of the manuscript, or the decision to submit the paper for publication.

\section{Availability of data and materials}

All relevant data are within the paper. Requests for additional information should be addressed to the corresponding author and data may be provided on reasonable request.

\section{Ethics approval and consent to participate}

Data were treated with full confidentiality in accordance with Italian legislation and no ethics committee's approval was needed. Before the database was made available to the authors, patient identifiers were replaced with anonymous codes. It was unnecessary to obtain patients' informed consent, given the anonymous nature of the data and its mandatory recording (anonymized data may be analyzed and used in aggregate form for scientific studies without further authorization). In fact, the data analysis was performed on anonymized aggregate data with no chance of individuals being identifiable. The study complied with the Declaration of Helsinki and with the recent resolution n. 9/2019 of the Italian Guarantor for the Protection of Personal Data which also confirmed the allowability of processing personal data for medical, biomedical and epidemiological research, and that data concerning health status may be used in aggregate form in scientific studies. To ensure confidentiality and anonymity Veneto Region removes all direct identifiers (e.g. identifier health code number) and substitutes with a code the identifier number in all data sets, nonetheless permitting the linkage of different administrative database.

\section{Consent for publication}

Not applicable.

\section{Competing interests}

The authors have no conflict of interest to disclose. Alessandra Buja is a member of the editorial board (Associate Editor) of this journal, but that they had no role in the editorial process of this article.

\section{Author details}

${ }^{1}$ Department of Cardiological, Thoracic and Vascular Sciences, Hygiene and Public Health Unit, University of Padua, Via Loredan 18, 35128 Padova, Italy. ${ }^{2}$ School of Specialization in Hygiene, Preventive Medicine and Public Health, University of Padua, Via Loredan 18, 35128 Padova, Italy. ${ }^{3}$ ULSS 6 Euganea, Via Enrico degli Scrovegni 14, 35131 Padova, Veneto Region, Italy.

${ }^{4}$ Department of Cardiological, Thoracic and Vascular Sciences, Legal Medicine Unit, University of Padua, Via Loredan 18, 35128 Padova, Italy. ${ }^{5}$ College of Public Health, University of Georgia, 125 Miller Hall, UGA Health Sciences, Athens, GA 30602, USA.

Received: 18 July 2019 Accepted: 30 December 2019

Published online: 14 January 2020

\section{References}

1. Ouslander JG, Maslow K. Geriatrics and the triple aim: defining preventable hospitalizations in the long-term care population. JAGS. 2012;60:2313-8.

2. Benbassat J, Taragin M. Hospital readmissions as a measure of quality of health care: advantages and limitations. Arch Intern Med. 2000;160(8):1074-81.

3. Fingar KR, Barret ML, Joanna Jiang H. A comparison of all-cause 7-day and 30-day readmissions. HCUP Statistical Brief \#230. 2014.

4. Min X, Yu B, Wang F. Predictive modeling of the hospital readmission risk from patients' claims data using machine learning: a case study on COPD. Sci Rep. 2019 Feb 20;9(1):2362.

5. Jiang $X$, Xiao H, Segal R, Mobley WC, Park H. Trends in readmission rates, hospital charges, and mortality for patients with chronic obstructive pulmonary disease (COPD) in Florida from 2009 to 2014. Clin Ther. 2018:40: 613-26

6. Dal Negro R, Rossi A, Cerveri I. The burden of COPD in Italy: results from the confronting COPD survey. Respir Med. 2003;97(C):S43-50.

7. Dreyer RP, Dharmarajan K, Hsieh AF, Welsh J, Qin L, Krumholz HM. Sex differences in trajectories of risk after Rehospitalization for heart failure, acute myocardial infarction, or pneumonia. Circ Cardiovasc Qual Outcomes. 2017 May; 10(5):e003271

8. Galdas PM, Cheater F, Marshall P. Men and health help-seeking behaviour: literature review. J Adv Nurs. 2005;49(6):616-23.

9. WHO Regional Office for Europe. The health and well-being of men in the WHO European Region: better health through a gender approach. Copenhagen; 2018. 
10. Woz S, Mitchell S, Hesko C, Paasche-Orlow M, Greenwald J, Chetty VK, O'Donnell J, Jack B. Gender as risk factor for 30 days post-discharge hospital utilisation: a secondary data analysis. BMJ Open. 2012;2(2):e000428.

11. Möller-Leimkühler AM. Barriers to help seeking by men: a review of sociocultural and clinical literature with particular reference to depression. J Affect Disord. 2002;71:1-9.

12. Baker P, Shand T. Men's health: time for a new approach to policy and practice? J Glob Health. 2017;7(1):010306.

13. Barik A, Rai RK, Gorain A, Majumdar S, Chowdhury A. Socio-economic disparities in tobacco consumption in rural India: evidence from a health and demographic surveillance system. Perspect Public Health. 2016;136:278-87.

14. Damiani G, Federico B, Venditti A, et al. Hospital discharge planning and continuity of care for aged people in an Italian local health unit: does the care-home model reduce hospital readmission and mortality rates? BMC Health Serv Res. 2009:9:22.

15. Galdas $P$, Fell J, Bower P, et al. The effectiveness of self management support interventions for men with long-term conditions: a systematic review and meta-analysis. BMJ Open. 2015;5:e006620.

\section{Publisher's Note}

Springer Nature remains neutral with regard to jurisdictional claims in published maps and institutional affiliations.

Ready to submit your research? Choose BMC and benefit from:

- fast, convenient online submission

- thorough peer review by experienced researchers in your field

- rapid publication on acceptance

- support for research data, including large and complex data types

- gold Open Access which fosters wider collaboration and increased citations

- maximum visibility for your research: over $100 \mathrm{M}$ website views per year

At BMC, research is always in progress.

Learn more biomedcentral.com/submissions 